\title{
Aproximación in silico a la evolución de la familia de genes que conforman el receptor ionotrópico de glutamato en cuatro especies de primates
}

\author{
Nury E. Vargas-Alejo ${ }^{1 *}$, Edgar A. Reyes-Montaño ${ }^{2 *}$, Leonardo Lareo ${ }^{1 \dagger}$ \\ ${ }^{1}$ Grupo de Bioquímica Computacional y Estructural y Bioinformática. Departamento de Nutrición y Bioquímica. Pontificia Universidad \\ Javeriana. Bogotá, D.C., Colombia. \\ ${ }^{2}$ Grupo de Investigación en Proteínas. Departamento de Química. Universidad Nacional de Colombia. Bogotá, D.C., Colombia \\ *nury.vargas@javeriana.edu.co; eareyesm@unal.edu.co
}

Recibido: 22-07-2010; Aceptado: 09-09-2010

\begin{abstract}
Resumen
El hombre como especie posee un cerebro único en capacidades de análisis por su estructura y patrones de organización que presumiblemente son la base de la inteligencia y la habilidad de manipular el entorno. Adicionalmente, el desarrollo y la evolución del cerebro responden los procesos genéticos subyacentes. Objetivo. Presentar una aproximación al proceso evolutivo de los iGluR con el método filogenético de máxima verosimilitud (ML) y bayesiano (By). Materiales y métodos. Para lo cual se emplean métodos in silico que permiten plantear un modelo de evolución molecular y el reconocimiento cualitativo de los bloques de sintenia, para estos genes en las especies de primates (chimpancé, orangután, mono rhesus y hombre). Resultados. El Glutamato es el principal neurotransmisor y juega un papel importante en la plasticidad neuronal y la neurotoxicidad. La neurotransmisión vía glutamato es mediada por los receptores ionotrópicos de Glutamato (iGluR) tipo NMDA y no-NMDA (AMPA y KA). Se tiene que por cada inferencia filogenética obtenida, se confirma que los iGluR de los mamíferos podrían haber evolucionado a partir de un mecanismo más primitivo de señalización, por lo cual se presentan agrupaciones similares entre algunas especies de primates con roedores Conclusión: Las secuencias de NR-2 han permanecido en una selección purificadora, y que la escala de divergencia neutral es más rápida en los primates que en los roedores; sin embargo es necesario aplicar otros estudios para confirman estas teorías de evolución.
\end{abstract}

Palabras clave: evolución en familias génicas, inferencia filogenética de ML y By, iGluR, AMPA, KA, NMDA.

\begin{abstract}
In silico approach to the evolution of ionotropic glutamate receptor gene family in four primate species. Man as a species has a brain unique in analysis capabilities due to its structure and organizational patterns that are presumably the basis of intelligence and the ability to manipulate the environment. Additionally, the development and evolution of the brain respond underlying genetic processes. Objective. To present an approach to the evolutionary process of the iGluR with the maximum likelihood (ML) and Bayesian (By) phylogenetic analysis methods. Materials and methods. we used in silico methods to propose a model of molecular evolution and to do a qualitative recognition of synteny blocks for these genes in different species of primates (chimpanzee, orangutan, rhesus monkey and man). Results. Glutamate is the main neurotransmitter and plays an important role in neuronal plasticity and neurotoxicity. Neurotransmission via glutamate is mediated by ionotropic glutamate receptors (iGluR) NMDA type and non-NMDA type (AMPA and KA). For every phylogenetic inference, we confirmed that the iGluRs of mammals could have evolved from a primitive signaling mechanism, thus explaining similar clusters between some species of primates and rodents. Conclusion. The NR-2 sequences have been exposed to a purifying selection, and the neutral level of divergence is faster in primates than in rodents, however further studies are needed to confirm these theories of evolution.
\end{abstract}

Key words: evolution in gene families, phylogenetic inference of ML and By, iGluR, AMPA, KA, NMDA. 


\section{Resumo}

Aproximação In silico á evolução da família de genes que compõem o receptor ionotrópico de Glutamato em quatro espécies de primatas. O homem como espécie tem um cérebro único em capacidades de análise por sua estrutura e padrões de organização que, presumivelmente, são a base da inteligência e da capacidade de manipular o meio ambiente. Além ao desenvolvimento e a evolução do cérebro, respondem os processos genéticos subjacentes. Objetivo. Apresentar uma aproximação ao processo evolutivo dos iGluR com o método filogenético de máxima verossimilhança (ML) e bayesiano (By.) Materiais e métodos. Foram empregados métodos in silico que permitem apresentar um modelo de evolução molecular e o reconhecimento qualitativo dos blocos de sintenia, para estes genes das espécies de primatas (chimpanzé, orangotango, o macaco rhesus e o homem). Resultados. O Glutamato é o principal neurotransmissor e desempenha um importante papel na plasticidade neuronal e na neurotoxicidade. A neurotransmissão via Glutamato é mediada pelos receptores ionotrópicos de Glutamato (iGluR) do tipo NMDA e no-NMDA (AMPA e KA). Foi observado que por cada inferência filogenética obtida, confirmase que os iGluR dos mamíferos poderiam ter evoluído a partir de um mecanismo mais primitivo de sinalização, pelo qual se apresentam agrupações semelhantes entre algumas espécies de primatas com roedores. Conclusão. As sequiências de NR-2 têm permanecido numa seleção purificadora, e que a escala de divergência neutral é mais rápida em primatas do que em roedores; embora, é necessario realizar outras pesquisas para confirmar estas teorias da evolução.

Palavras-chave: evolução em família génicas, inferência filogenética de ML y By, iGluR, AMPA, KA, NMDA.

\section{Introducción}

El cerebro humano es considerado grande en relación al tamaño de su cuerpo y comparado con otras especies animales. Los genes que controlan el tamaño y la complejidad del cerebro han experimentado una evolución mucho más rápida en los seres humanos que en primates no humanos u otros mamíferos $(1,23)$. Hasta el momento se encuentran investigaciones realizadas a genes de cerebro relacionadas con: genes de microcefalia (MCPH1), Abnormal spindle-like microcephaly associated (ASPM) y el gen de la enzima Glutamato Deshidrogenasa (GDH) que está relacionado con el metabolismo del glutamato y su reciclaje; siendo estos factores genéticos combinados los determinantes para la progresiva evolución del cerebro de los Hominidae incluyendo el asombroso avance del cerebro del hombre $(4,5)$.

El glutamato, principal neurotransmisor, juega un papel importante en la plasticidad neuronal y la neurotoxicidad. La neurotransmisión vía glutamato es mediada por una serie de receptores, los cuales son clasificados de acuerdo a la selectividad y afinidad del receptor a su agonista -NMDA, AMPA y kainato- (6-12). El receptor activado por $N$-metil$D$-aspartato (iGluR-NMDA) es expresado hasta por siete diferentes genes denominados GRIN, los cuales codifican las subunidades proteicas que conforman el receptor (13, 14). La transcripción es altamente regulada dependiendo del nivel de desarrollo, edad y tejido en el cual se expresa $(15,16)$. Los otros dos receptores de glutamato son denominados receptores inotrópicos de glutamato no-NMDA y están conformados por $\alpha$-amino-3-hidroxi-5-metil-4isoxazolepropionato (iGluR-AMPA), el cual se encuentra codificado por los genes GRIA 1 a 4. Y el sensible al ácido kaínico (iGluR-KA o iGluR-Kainato) el cual se encuentra codificado por los genes GRIK 1 a $5 .(17,18,19)$.
Dentro de esta familia de receptores ionotrópicos de glutamato (iGluR) se ha determinado la función primordial del receptor NMDA en los procesos de memoria y aprendizaje, por lo cual es considerado como un receptor esencial en las funciones cognitivas más complejas del hombre. Estudios del receptor NMDA en roedores han mostrado la importancia del dominio intracelular C-terminal, el cual conforma un complejo de señalización con enzimas y proteínas que regulan la plasticidad neuronal y comportamiento de manera particular para esta especie (20). Además se ha establecido una adaptación evolutiva especifica de los vertebrados de las subunidades NR2 del receptor NMDA en la región conformada por el C-terminal, en donde se propone que esta región se ha desarrollado para ser un centro de forma nativa no estructurado y flexible relacionado en la organización de la señalización postsináptica; la evolución de estas subunidades y su complejo de señalización asociados pueden contribuir a las diferencias en el comportamiento y función cognitiva particular de cada especie de invertebrados y vertebrados (20).

En este artículo se presenta una aproximación al proceso evolutivo de la familia de genes que codifican a los receptores inotrópicos de Glutamato (iGLuR), para lo cual se emplean métodos in silico que permiten establecer los cambios sucedidos en las regiones de las secuencias codificantes y a partir de estos, plantear una hipótesis de evolución molecular con la cual se construyen los respectivos árboles filogenéticos por métodos de máxima verosimilitud y bayesianos. La topología de los árboles permite encontrar la relación de las sustituciones no-sinónimas y sinónimas en cada rama, lo cual proporciona evidencia del tipo de selección que soportaron estos cDNAs. Finalmente se realiza una comparación genómica cualitativa de los bloques de sintenia de estos genes en las especies de primates (chimpancé, orangután, mono rhesus y hombre). 
Tabla 1: Resumen de las secuencias seleccionadas

\begin{tabular}{|c|c|c|c|c|c|c|c|}
\hline RECEPTOR & GEN & $\begin{array}{c}\text { RATTUS } \\
\text { NORVEGICUS }\end{array}$ & MUS MUSCULUS & HOMO SAPIENS & PAN TROGLODYTES & PONGO PYGMAEUS & MACACA MULATTA \\
\hline \multirow{7}{*}{ NMDA } & Grin 1 & $\begin{array}{c}\text { GeneID: } 24408 \\
\text { ENSRNOG0000001 } \\
1726\end{array}$ & $\begin{array}{c}\text { GenelD: } 14810 \mathrm{~V} \\
\text { ENSMUSG0000002 } \\
6959\end{array}$ & $\begin{array}{c}\text { GenelD: } 2902 \\
\text { ENSG000001768 } \\
84 \\
\end{array}$ & $\begin{array}{c}\text { ENSPTRG00000021 } \\
594\end{array}$ & $\begin{array}{l}\text { ENSPPYG00000019 } \\
809\end{array}$ & $\begin{array}{c}\text { GenelD: } 574380 \\
\text { ENSMMUG000000016 } \\
61\end{array}$ \\
\hline & Grin2a & $\begin{array}{c}\text { GenelD: } 24409 \\
\text { ENSRNOG0000003 } \\
3942 \\
\end{array}$ & $\begin{array}{c}\text { GenelD: } 14811 \\
\text { ENSMUSG0000005 } \\
9003\end{array}$ & $\begin{array}{c}\text { GenelD: } 2903 \\
\text { ENSG000001834 } \\
54 \\
\end{array}$ & $\begin{array}{c}\text { GenelD: } 454396 \\
\text { ENSPTRG00000007 } \\
754 \\
\end{array}$ & $\begin{array}{c}\text { ENSPPYG00000007 } \\
089 \\
\end{array}$ & $\begin{array}{c}\text { ENSMMUG000000101 } \\
42 \\
\end{array}$ \\
\hline & Grin2b & $\begin{array}{c}\text { GenelD: } 24410 \\
\text { ENSRNOG0000000 } \\
8766 \\
\end{array}$ & $\begin{array}{c}\text { GenelD: } 14812 \\
\text { ENSMUSG0000003 } \\
0209 \\
\end{array}$ & $\begin{array}{c}\text { GenelD: } 2904 \\
\text { ENSG000001500 } \\
86 \\
\end{array}$ & $\begin{array}{c}\text { GenelD: } 473373 \\
\text { ENSPTRG00000004 } \\
718 \\
\end{array}$ & $\begin{array}{c}\text { ENSPPYG00000004 } \\
317 \\
\end{array}$ & $\begin{array}{c}\text { GenelD: } 698571 \\
\text { ENSMMUG000000191 } \\
12 \\
\end{array}$ \\
\hline & Grin 2C & $\begin{array}{c}\text { GenelD: } 9721 \\
\text { ENSG00000204175 }\end{array}$ & $\begin{array}{c}\text { GenelD: } 14813 \\
\text { ENSMUSG0000002 } \\
0734\end{array}$ & $\begin{array}{c}\text { GenelD: } 2905 \\
\text { ENSG000001615 } \\
09\end{array}$ & $\begin{array}{c}\text { GenelD: } 454868 \\
\text { ENSPTRG00000009 } \\
619\end{array}$ & $\begin{array}{c}\text { ENSPPYG00000008 } \\
606\end{array}$ & $\begin{array}{c}\text { GenelD: } 699216 \\
\text { ENSMMUG000000057 } \\
44\end{array}$ \\
\hline & Grin2d & $\begin{array}{c}\text { GenelD: } 24412 \\
\text { ENSRNOG0000002 } \\
1063\end{array}$ & $\begin{array}{c}\text { GenelD: } 14814 \\
\text { ENSMUSG0000000 } \\
2771 \\
\end{array}$ & $\begin{array}{c}\text { GenelD: } 2906 \\
\text { ENSG000001054 } \\
64 \\
\end{array}$ & & $\begin{array}{l}\text { ENSPPYG00000010 } \\
198 \\
\end{array}$ & $\begin{array}{c}\text { ENSMMUG000000059 } \\
83 \\
\end{array}$ \\
\hline & Grin3a & $\begin{array}{c}\text { GenelD: } 191573 \\
\text { ENSRNOG0000000 } \\
5723 \\
\end{array}$ & $\begin{array}{c}\text { GeneID: } 242443 \\
\text { ENSMUSG0000003 } \\
9579 \\
\end{array}$ & $\begin{array}{c}\text { GenelD: } 116443 \\
\text { ENSG000001987 } \\
85 \\
\end{array}$ & $\begin{array}{c}\text { GenelD: } 736408 \\
\text { ENSPTRG00000023 } \\
608 \\
\end{array}$ & $\begin{array}{c}\text { ENSPPYG00000019 } \\
456 \\
\end{array}$ & $\begin{array}{c}\text { GenelD: } 716892 \\
\text { ENSMMUG000000166 } \\
75\end{array}$ \\
\hline & Grin3b & $\begin{array}{c}\text { GenelD: } 170796 \\
\text { ENSRNOG0000001 } \\
2562 \\
\end{array}$ & $\begin{array}{c}\text { GenelD: } 170483 \\
\text { ENSMUSG0000003 } \\
5745 \\
\end{array}$ & $\begin{array}{c}\text { GenelD: } 116444 \\
\text { ENSG000001160 } \\
32\end{array}$ & $\begin{array}{c}\text { ENSPTRG00000010 } \\
175 \\
\end{array}$ & & \\
\hline \multirow{5}{*}{ AMPA } & Gria1 & & $\begin{array}{c}\text { GenelD: } 14799 \\
\text { ENSMUSG0000002 } \\
0524\end{array}$ & $\begin{array}{c}\text { GenelD: } 2890 \\
\text { ENSG000001555 } \\
11 \\
\end{array}$ & $\begin{array}{c}\text { GenelD: } 471714 \\
\text { ENSPTRG00000017 } \\
441 \\
\end{array}$ & $\begin{array}{c}\text { ENSPPYG00000015 } \\
970\end{array}$ & $\begin{array}{c}\text { GenelD: } 714117 \\
\text { ENSMMUG000000092 } \\
87\end{array}$ \\
\hline & Gria2 & $\begin{array}{c}\text { GenelD: } 29627 \\
\text { ENSRNOG0000002 } \\
8589 \\
\end{array}$ & $\begin{array}{c}\text { GenelD: } 14800 \\
\text { ENSMUSG0000003 } \\
3981 \\
\end{array}$ & $\begin{array}{c}\text { GenelD: } 2891 \\
\text { ENSG000001202 } \\
51 \\
\end{array}$ & $\begin{array}{c}\text { GenelD: } 461570 \\
\text { ENSPTRG00000016 } \\
548 \\
\end{array}$ & $\begin{array}{c}\text { ENSPPYG00000015 } \\
153 \\
\end{array}$ & $\begin{array}{c}\text { GenelD: } 574344 \\
\text { ENSMMUG000000182 } \\
72\end{array}$ \\
\hline & & $\begin{array}{c}\text { GenelD: } 29628 \\
\text { ENSRNOG0000000 }\end{array}$ & $\begin{array}{c}\text { GenelD: } 53623 \\
\text { ENSMUSG0000000 }\end{array}$ & $\begin{array}{c}\text { GenelD: } 2892 \\
\text { ENSG000001256 }\end{array}$ & $\begin{array}{c}\text { GenelD: } 465842 \\
\text { ENSPTRG00000022 }\end{array}$ & & $\begin{array}{c}\text { GenelD: } 698396 \\
\text { ENSMMUG000000090 }\end{array}$ \\
\hline & Gria3 & 7682 & 1986 & 75 & 245 & & 54 \\
\hline & Gria4 & $\begin{array}{c}\text { GenelD: } 29629 \\
\text { ENSRNOG0000000 } \\
6957\end{array}$ & $\begin{array}{c}\text { GenelD: } 14802 \\
\text { ENSMUSG0000002 } \\
5892\end{array}$ & $\begin{array}{c}\text { GenelD: } 2893 \\
\text { ENSG000001525 } \\
78\end{array}$ & $\begin{array}{c}\text { GenelD: } 466768 \\
\text { ENSPTRG00000004 } \\
233\end{array}$ & & $\begin{array}{c}\text { ENSMMUG000000109 } \\
87\end{array}$ \\
\hline \multirow{5}{*}{ KAINATE } & Grik1 & $\begin{array}{c}\text { GenelD: } 29559 \\
\text { ENSRNOG0000000 } \\
1575\end{array}$ & $\begin{array}{c}\text { GenelD: } 14805 \\
\text { ENSMUSG0000002 } \\
2935\end{array}$ & $\begin{array}{c}\text { GenelD: } 2897 \\
\text { ENSG000001711 } \\
89 \\
\end{array}$ & $\begin{array}{c}\text { GenelD: } 474083 \\
\text { ENSPTRG00000013 } \\
825 \\
\end{array}$ & $\begin{array}{c}\text { ENSPPYG00000011 } \\
323\end{array}$ & $\begin{array}{l}\text { ENSMMUG000000048 } \\
86 \\
\end{array}$ \\
\hline & Grik2 & $\begin{array}{c}\text { GenelD: } 54257 \\
\text { ENSRNOG0000000 } \\
0368 \\
\end{array}$ & $\begin{array}{c}\text { GenelD: } 14806 \\
\text { ENSMUSG0000005 } \\
6073 \\
\end{array}$ & $\begin{array}{c}\text { GenelD: } 2898 \\
\text { ENSG000001644 } \\
18 \\
\end{array}$ & $\begin{array}{c}\text { GenelD: } 462899 \\
\text { ENSPTRG00000018 } \\
449 \\
\end{array}$ & $\begin{array}{c}\text { ENSPPYG00000016 } \\
870 \\
\end{array}$ & $\begin{array}{c}\text { ENSMMUG000000295 } \\
27 \\
\end{array}$ \\
\hline & Grik3 & $\begin{array}{l}\text { ENSRNOG0000000 } \\
8992 \\
\end{array}$ & $\begin{array}{c}\text { GenelD: } 14807 \\
\text { ENSMUSG0000000 } \\
1985\end{array}$ & $\begin{array}{c}\text { GenelD: } 2899 \\
\text { ENSG000001638 } \\
73 \\
\end{array}$ & $\begin{array}{c}\text { GenelD: } 469281 \\
\text { ENSPTRG00000000 } \\
543 \\
\end{array}$ & $\begin{array}{c}\text { ENSPPYG00000001 } \\
535\end{array}$ & $\begin{array}{c}\text { GenelD: } 713545 \\
\text { ENSMMUG000000096 } \\
79\end{array}$ \\
\hline & Grik4 & $\begin{array}{c}\text { GenelD: } 24406 \\
\text { ENSRNOG0000003 } \\
0910\end{array}$ & $\begin{array}{c}\text { GenelD: } 110637 \\
\text { ENSMUSG0000003 } \\
2017\end{array}$ & $\begin{array}{c}\text { GenelD: } 2900 \\
\text { ENSG000001494 } \\
03\end{array}$ & $\begin{array}{c}\text { GenelD: } 451620 \\
\text { ENSPTRG00000004 } \\
394\end{array}$ & $\begin{array}{c}\text { ENSPPYG00000003 } \\
977\end{array}$ & $\begin{array}{c}\text { GenelD: } 706383 \\
\text { ENSMMUG000000223 } \\
47\end{array}$ \\
\hline & Grik5 & $\begin{array}{c}\text { GenelD: } 24407 \\
\text { ENSRNOG0000002 } \\
0310\end{array}$ & $\begin{array}{c}\text { GenelD: } 14809 \\
\text { ENSMUSG0000000 } \\
3378\end{array}$ & $\begin{array}{c}\text { GenelD: } 2901 \\
\text { ENSG000001057 } \\
37\end{array}$ & $\begin{array}{c}\text { GenelD: } 469084 \\
\text { ENSPTRG00000011 } \\
042\end{array}$ & $\begin{array}{c}\text { ENSPPYG00000010 } \\
034\end{array}$ & $\begin{array}{c}\text { ENSMMUG000000174 } \\
31\end{array}$ \\
\hline
\end{tabular}

En esta tabla se presenta la información de la siguiente manera: columna 1 el nombre del receptor, columna 2 nombre del gen, columnas 3 a 8 nombre de la especie y de cada una se anota el ID de NCBI y ID de Ensembl. Los espacios en blanco son genes no anotados por lo cual no son utilizados dentro de los diferentes procesos de inferencia filogenética.

\section{Materiales y métodos}

\section{Selección de OTUs y generación de la bases de datos}

De acuerdo a lo reportado en la literatura se seleccionaron especies relacionadas con el hombre (Homo sapiens) que pertenezcan al orden de los Primates. Paralelamente se establecieron las especies que formaron el grupo externo, las cuales pertenecen al orden Rodentia. Después se realizó la búsqueda de los genes y de los respectivos cDNAs anotados para el hombre en la bases de datos de Ensembl (http://www.ensembl.org/index.html) los ID de las secuencias obtenidas se registran en la tabla 1 . Se realizaron los respectivos archivos de las secuencias de cada cDNA correspondientes a cada receptor por especie en estudio. Estos cDNA agrupan todos los posibles transcriptos generados por los genes en eventos de splicing y que cumplen con ser cDNA de la familia de los genes de iGluR. 


\section{Alineamiento múltiple y curación}

Se generan alineamientos con la herramienta de Muscle 3.7 (Multiple Sequence Comparison by Log-Expectation (http://www.drive5.com/muscle/downloads.htm) Dentro de los parámetros seleccionados se estableció que se realizara un alineamiento total, con un mínimo de 16 ciclos (repeticiones) y sin buscar diagonales. Se identificaron los sitios conservados y los sitios informativos en cada alineamiento. La curación de los alineamientos se realizó a través del programa Gblocks (http://molevol.cmima.csic.es/castresana/Gblocks_server.html).

\section{Generación de árboles filogenéticos}

Para cada set de datos se determinó la hipótesis de evolución molecular utilizando los programas: PhyML 3.0 (http:/ /phylogeny.lirmm.fr/phylo_cgi/index.cgi), TreeFinder (http://www.treefinder.de/), y jModelTest 0.1.1 (http:// darwin.uvigo.es/software/jmodeltest.html) Después se aplicó la prueba de máxima verosimilitud (LTR) y la prueba de criterio de información (AIC), estas se encuentran disponibles en el programa jModelTest. Se seleccionó el modelo correspondiente, que presentó óptimos valores en LTR y AIC (Tabla 2). Luego se generaron los árboles por receptor y especie, bajo criterios de ML con el programa TreeFinder con prueba de confiabilidad - Bootstrap de 1000 repeticiones; también se generaron árboles por especie bajo inferencia Bayesiana con el programa Mr. Bayes (http://mrbayes.csit.fsu.edu/download.php.) Para este análisis se tomó como parámetros: mcmc (Markov chain Monte Carlo) ngen=10000 (número de ciclos del algoritmo de mcmc) y samplefreq=10; sump-burnin=250 y sumtburnin=250. A partir de la inferencia filogenética se determinó la relación de sustituciones no-sinónimas y sinónimas, empleando el programa CODEML de PAML (http://abacus.gene.ucl.ac.uk/software/paml.html o en http://www.treedyn.org/.). Finalmente se analizó la información obtenida en cada árbol y se comparó con los bloques de sintenia de cada gen reportado en la Base de Datos de Ensembl.

\section{Resultados}

\section{Selección de OTUs}

Después de observar la distribución de los genes de iGluR en cada una de las especies, se estableció que los genes codificantes de las subunidades del receptor AMPA, contienen repeticiones intrón-exón (21), notando que esta estructura es predominante en los genes de iGluR. Al mismo tiempo se apreció que los genes de iGluR se encuentran distribuidos por los cromosomas de las diferentes especies, ubicándose en un promedio de 11 de ellos con una tendencia a las regiones del extremo derecho o brazo largo; sin embargo en la especie de macaco la región favorecida es el extremo izquierdo de los cromosomas. En la ocurrencia de dos genes en el mismo cromosoma se identificó que rata y ratón comparten la ubicación de Grin-2D y Grik-5 y de Gria-4 y Grik-4; el ratón posee mayor cantidad de cromosomas con dos genes de iGluR.

La característica de los primates es que la especie macaco no tiene un comportamiento similar a las otras especies, mientras que los genes de humano, chimpancé y orangután comparten la misma distribución cromosómica, y estas especies comparten la similitud de ubicar en el cromosoma 9 los genes de Grin-1 y Grin-3A, cromosoma 11 los genes de Gria-4 y Grik-4 y en el cromosoma 19 los genes de Grin-2D y Grik-5 en el brazo largo y el gen de Grin-3B

Tabla 2: Pruebas estadísticas para la selección del modelo de evolución molecular. Prueba de razón de verosimilitud (LRT) con $\alpha=0,01$ y prueba de Criterio de información (AIC).

\begin{tabular}{lccccc}
\hline especie & Log-Likehood & Modelo & LTR & \multicolumn{2}{c}{ AIC } \\
\cline { 5 - 6 } & & & 5,38 & 0,0 & $\omega$ \\
\hline Humano & $-22074,38$ & GTR $+\mathrm{G}$ & 2,54 & 0,0 & 0,6159 \\
Chimpancé & $-15055,30$ & GTR+G & 8,34 & 0,0 & 0,2185 \\
Orangután & $-20097,12$ & GTR+I+G & 3,3 & 0,0 & 0,757 \\
Macaco & $-18996,86$ & GTR+G & 912,46 & 0,0 & 0,3767 \\
Rata & $-25258,62$ & GTR+I+G & 0,020 & 0,0 & 0,5493 \\
ratón & $-20824,93$ & GTR+G & 0,5744 \\
\hline
\end{tabular}


en el brazo corto. La ubicación de estas parejas de genes permiten establecer que en las especies del orden de primates y roedores los genes de Grin-2D y Grik-5, y de Gria-4 y Grik-4 siempre se ubican cercanas sobre el mismo cromosoma (9), se determina entonces para los primates que los genes de Grin-2D y Grik-5 tienen la tendencia a ubicarse en el brazo largo y que pueden ir acompañados del gen de Grin-3B pero con la preferencia por ubicarse en el brazo corto del cromosoma o región izquierda si es un cromosoma de tipo telocéntrico.

De los genes que presentan procesos de splicing en donde se originan diversos cDNAs se encuentra los genes de Grin1, Gria-2, Grik-1 y Grik-2. El gen de Gria-3 se ubica en el cromosoma $\mathrm{X}$ para todas las especies, al tiempo se identifica que en ellas los cromosomas 13, 18, 22 y Y no soportan ningún gen de iGluR. Por el comportamiento descrito anteriormente de esta familia génica se evidencia que los eventos de duplicación no han generado procesos de repeticiones continuas o repeticiones en tándem, por lo cual se postula que su proceso de cambio está relacionado con eventos de duplicación y divergencia de genes $(22,23)$.

\section{Alineamientos múltiples y curación}

En la información que se puede recopilar de los alineamientos, se evidencia que se presentan regiones de bloques muy definidos y cortos los cuales son conservados, estos bloques son especialmente formados entre los genes que codifican para un mismo receptor, también se identificaron regiones que forman grandes gaps que varían entre 50 a 100 sitios y en donde solo aparecen secuencias de una determinada subunidad. De este tipo de alineamientos a nivel de secuencias de cDNA no se tienen reportes y lo más cercano es el alineamiento realizado por Das, et al, 1998 (24), de las secuencias de aminoácidos de ratón, en donde se establece una similaridad del $80 \%$ entre ellas. Lo importante de estos alineamientos de cDNA es que permiten ver el comportamiento de las secuencias dentro de una especie y evidenciar los sitios conservados para cada receptor e incluso permite ver los sitios que son conservados en todas las secuencias, aunque estos son muy cortos y poco frecuentes.

\section{Inferencia filogenética}

La determinación de la hipótesis de evolución molecular es importante por sus consecuencias en la estimación filogenética, esta nos permite establecer frecuencia y tasa de cambio entre los nucleótidos que conforman una secuencia dentro de un alineamiento, desde el modelo establecido, en este caso el modelo GTR con alguno de los ajustes $(+\mathrm{I},+\mathrm{G},+\mathrm{IG})$ nos permite generar una simplificación matemática de un proceso natural. Sin embargo, en estos modelos solo se puede evidenciar los nucleótidos que están presentes en las secuencias actuales y no podemos identificar los estados apomórficos del carácter, motivo por el cual se plantea como hipótesis nula que las variaciones internas de los caracteres tienen la tendencia a ser mutaciones al azar con poca o ninguna influencia en la funcionalidad de la proteína.

\section{Humano (Homo sapiens), rata (Rattus norvegicus) y ratón (Mus musculus)}

De la estimación filogenética del hombre, la rata y el ratón, se tiene la generación de dos árboles uno por el método ML y otro por el método By, en ambos casos el modelo de evolución utilizado para el hombre fue GTR $+\mathrm{G}$, para la rata fue GTR+I+G y para el ratón fue GTR+G (Figura 1A y B). Estas tres especies presentan una topología similar en sus árboles pero diferente comparado con las otras especies de primates.

De la topología del árbol se puede observar dos agrupaciones originadas desde el ancestro común, estas son: una agrupación cerca a la línea parental que contiene las secuencias del receptor tipo NMDA y otra agrupación que surge después de un evento de duplicación que orienta a las secuencias de los receptores tipo no-NMDA. Dentro de la agrupación tipo NMDA se tiene que las secuencias más cercanas al ancestro son las de Grin-1 que a partir de ella sucede el evento de duplicación que termina en genes de Grin-2 y genes de Grin-3, de estos, la agrupación de los genes de Grin-2 demuestran que existe más relación entre los genes de Grin-2A y Grin-2B y los genes de Grin-2C y Grin-2D, al igual que entre los genes de Grin-3A y Grin-3B se establece mayor relación.

De la agrupación de los receptores tipo no-NMDA se tiene que, en la agrupación de AMPA la secuencia más cercana al ancestro común es la secuencia de Gria-1 y a partir de ella surgen las secuencias de Gria-2 que conducen a la formación de las secuencias de Gria-3 y Gria-4, estas últimas están relacionadas por tener el mismo cen-ancestro. De las secuencias que forman el receptor de Kainato, se pueden observar dos agrupaciones internas, la primera orienta a la secuencia de Grik-3 en donde sucede un evento de duplicación que lleva a las secuencias de Grik-1 y Grik-2; en la otra agrupación se encuentran las secuencias de Grik-4 y Grik-5. Por la determinación de la relación existente entre los sitios no-sinónimos y los sinónimos (valor $=\omega: \mathrm{dN} / \mathrm{dS}$ ), el cual es una característica de cada nodo e indica el tipo de selección que actúa sobre las se- 


\section{iGluR_HUMANO}

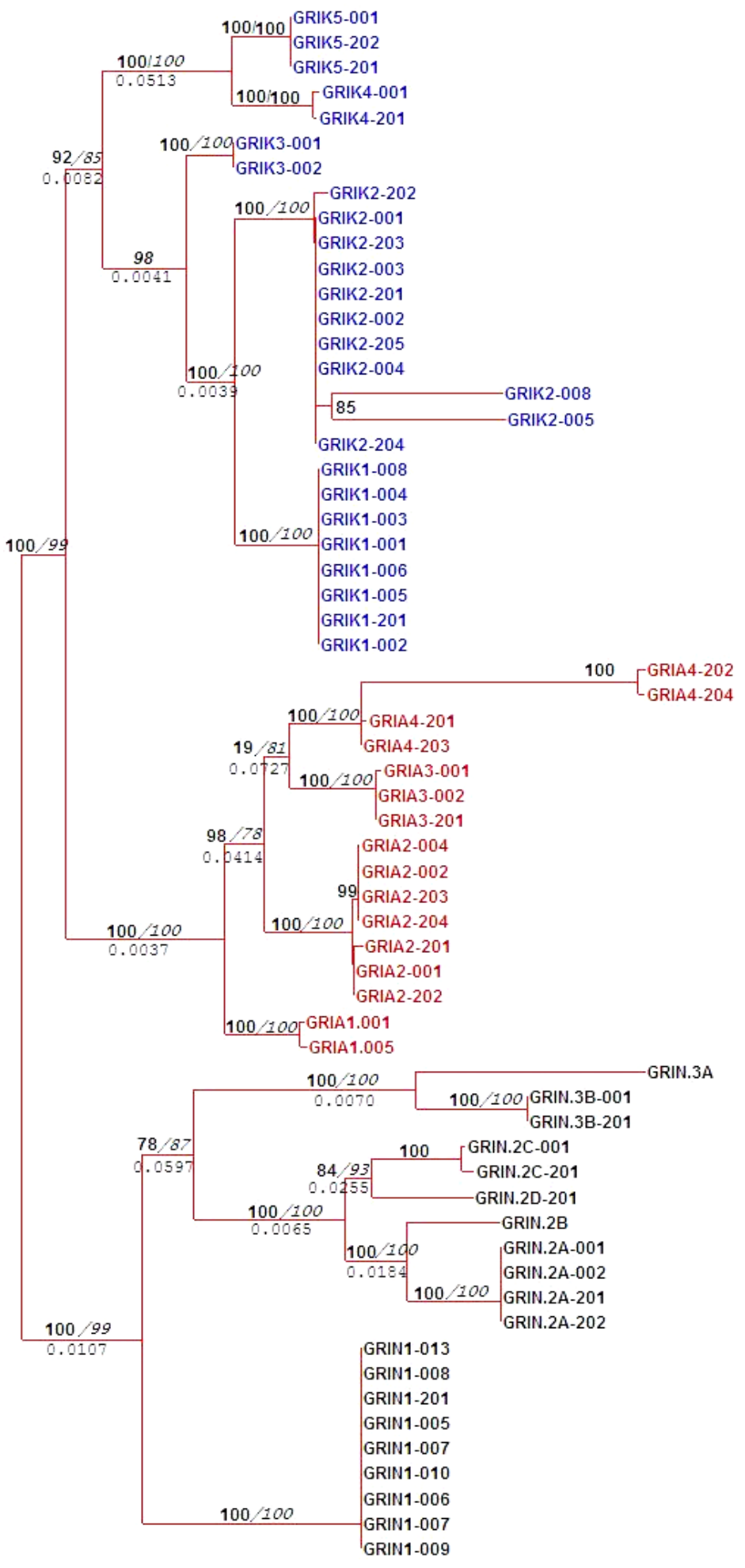

A

Figura 1. Árboles filogenéticos de las especies hombre (A), rata y ratón (B); en donde se observan los receptores inotrópicos de Glutamato NMDA; AMPA y KA (kainato) generados a partir de las secuencias de cDNA, en las ramas del árbol se indica el valor de bootstrap (negrilla-ML y cursiva-By) y la proporción de sustituciones no-sinónimas con relación a las sustituciones sinónimas $(\omega)$. Los rombos indican cada grupo farmacológico y el triángulo indica los genes parálogos de Grin-2. 

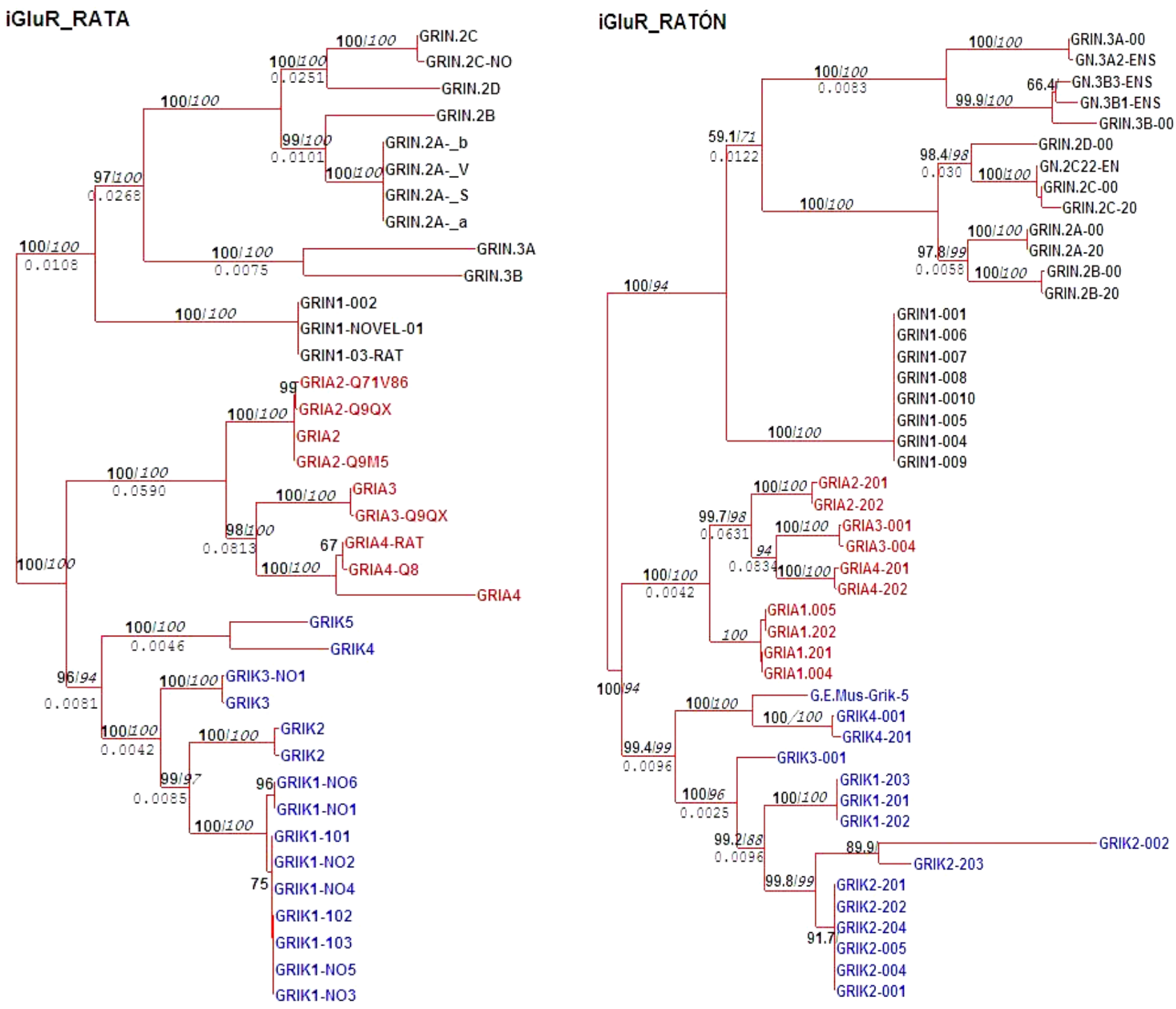

B

Figura 1. Árboles filogenéticos de las especies hombre (A), rata y ratón (B); en donde se observan los receptores inotrópicos de Glutamato NMDA; AMPA y KA (kainato) generados a partir de las secuencias de cDNA, en las ramas del árbol se indica el valor de bootstrap (negrilla-ML y cursiva-By) y la proporción de sustituciones no-sinónimas con relación a las sustituciones sinónimas $(\omega)$. Los rombos indican cada grupo farmacológico y el triángulo indica los genes parálogos de Grin-2.

cuencias, se tiene el siguiente rango: $\omega=1$ indica que las secuencias en la rama siguen un modelo estrictamente neutro; $\omega<1$ indica que sobre las secuencias de la rama actúa una selección purificadora o negativa y $\omega>1$ en donde el tipo de selección es positiva, para el caso de estos árboles se tiene que en los resultados de $\omega$ favorecen los eventos de selección purificadora, lo cual indicaría que las sustituciones no-sinónimas son detrimentales de la estructura y/o función de la proteína.

\section{Chimpancé (Pan troglodytes) y orangután (Pongo pygmaeus)}

De la estimación filogenética del chimpancé y del orangután se tiene la generación de dos árboles uno por el método ML y otro por el método By, en ambos casos el modelo de evolución utilizado fue GTR+G para chimpancé y GTR $+\mathrm{I}+\mathrm{G}$ para orangután (Figura 2). En estos árboles el comportamiento y agrupación de las secuencias es igual 
entre ellos pero diferente a la topología establecida para el hombre y macaco. En estos árboles se tiene que a partir del ancestro común existen dos grandes agrupaciones, pero estas no corresponden a la clasificación farmacológica (tipo NMDA y no-NMDA). De la primera agrupación se observa que las secuencias de Grin-2A y Grin-2B están relacionadas entre ellas al tener el mismo cen-ancestro, ellas surgen de la secuencia de Grin-2C, paralelo a este grupo se encuentra la secuencia de Grin-3A y Grin-3B que están relacionadas por el linaje ancestral. De la segunda agrupación se aprecia que la secuencia sobre la cual sucede el evento de duplicación es la de Grin-1 y ésta orienta a la formación de las otras secuencias en dos grupos: AMPA y KA, es por el cambio en esta secuencia de Grin-1 que no se cumple con la clasificación farmacológica establecida. En AMPA la secuencia más cercana al ancestro es la de Gria-1 de ella surge la secuencia de Gria-2 y de esta se generan las secuencias de Gria-4 y Gria-3. En el grupo de KA, se observa un nodo en donde se genera la divergencia entre las secuencias de Grik-4 y Grik-5 muy relacionadas por tener un gen-ancestro y en el otro grupo las secuencias de Grik-3 orientan a la formación de Grik-2 y Grik-1. Por la determi-

\section{IGluR_CHIMPANCÉ}

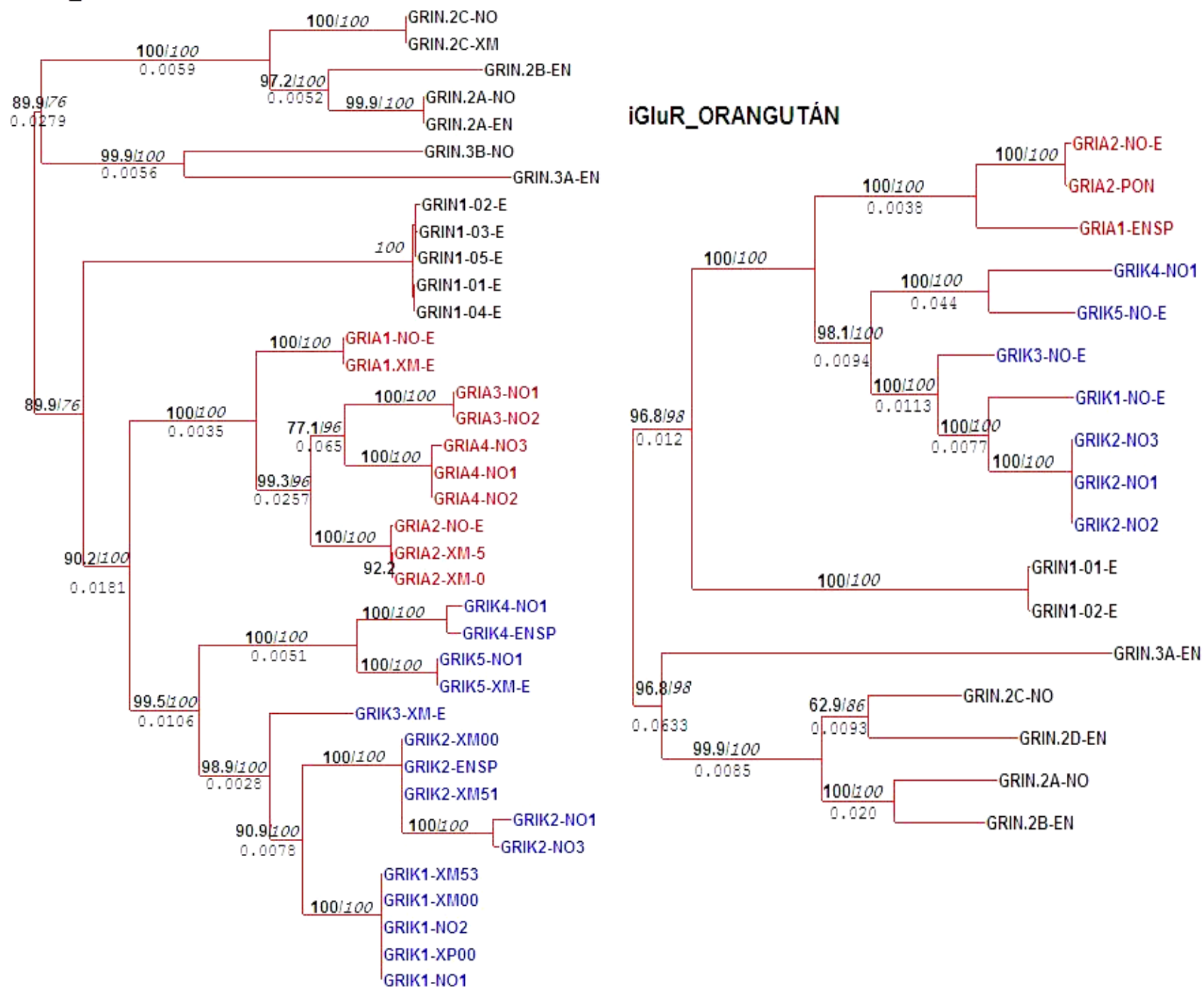

Figura 2. Árboles filogenéticos de las especies chimpancé y orangután; en donde se observan los receptores inotrópicos de Glutamato NMDA; AMPA y KA (kainato) generados a partir de las secuencias de cDNA, en las ramas del árbol se indica el valor de bootstrap (negrilla-ML y cursiva-By) y la proporción de sustituciones no-sinónimas con relación a las sustituciones sinónimas $(\omega)$. Los rombos indican cada grupo farmacológico y el triángulo indica los genes parálogos de Grin-2. 
nación de la relación existente entre los sitios no-sinónimos y los sinónimos (valor= $\omega: \mathrm{dN} / \mathrm{dS}$ ), se observa que esta relación es menor a 1 , lo cual indica que el tipo de selección que actúa sobre estas secuencias es negativa.

\section{Macaco o mono rhesus (Macaca mulatta)}

De la estimación filogenética del macaco se tiene la generación de dos árboles uno por el método ML y otro por el método By, en ambos casos el modelo de evolución utilizado fue GTR+G (Figura 3). La topología presentada por el árbol de esta especie no se parece a ninguna establecida para otra especie ni de roedores ni de primates, por lo cual el comportamiento de estas secuencias es particular a la espe- cie. Del árbol se tiene que desde el ancestro ocurre un evento de duplicación que orienta a la formación de dos agrupaciones, la primera de ellas orienta la formación de KA y NMDA y la segunda orienta la formación de AMPA; en la agrupación de NMDA se observa cómo la secuencia más cercana al ancestro es la de Grik-2 y a partir de ella ocurre un evento de duplicación en donde se origina la secuencia de Grin-1 y de esta se forman las secuencias de Grin 3A por un lado y las secuencias de Grin-2A y Grin-2B, y de Grin-2C y Grin-2D las cuales están más relacionadas por presentar un cen-ancestro para cada secuencia de Grin-2.

En la agrupación de KA se tiene un evento de duplicación sucedido a partir del ancestro en donde se establece la

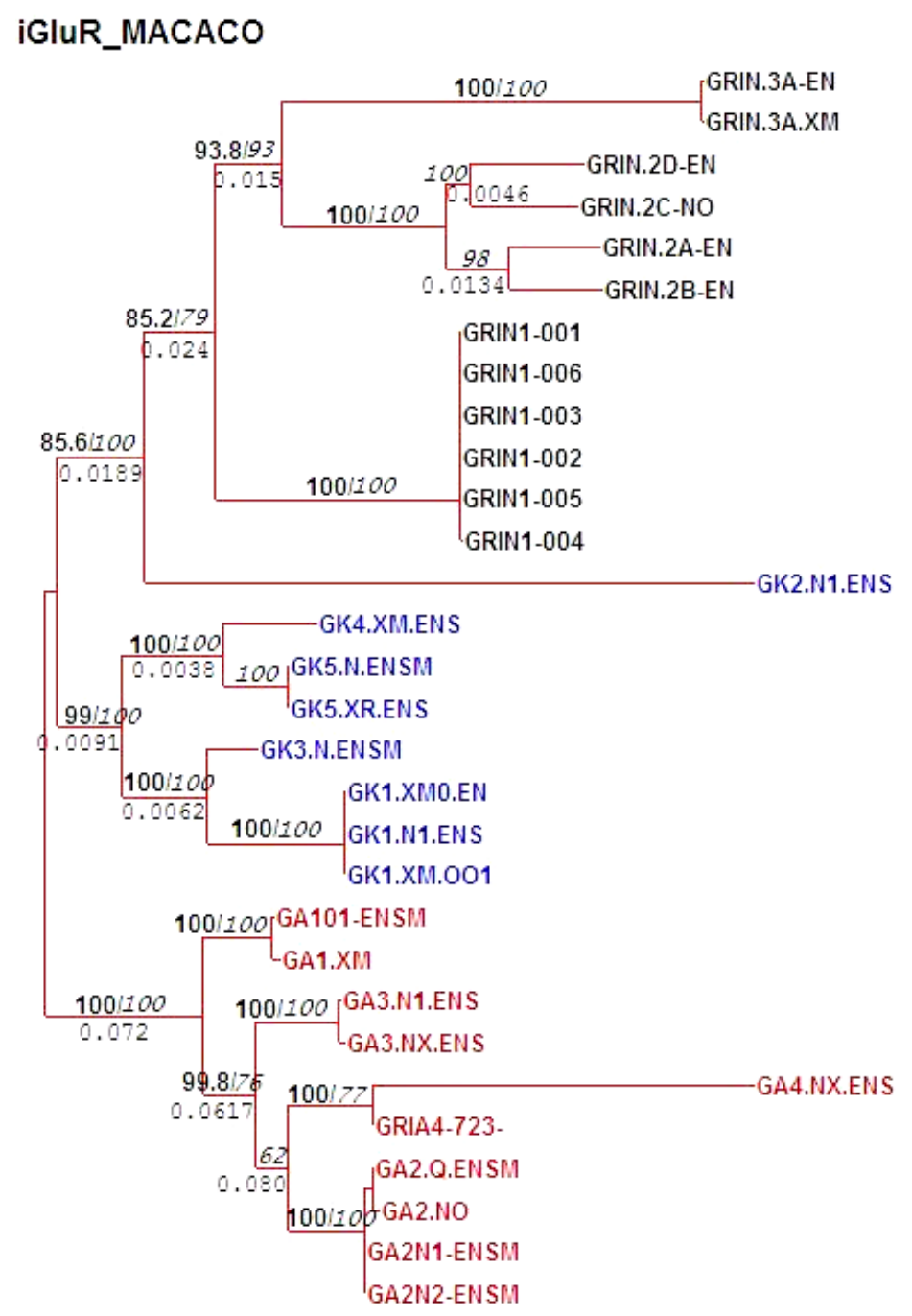

Figura 3. Árboles filogenéticos de las especies chimpancé y orangután; en donde se observan los receptores inotrópicos de Glutamato NMDA; AMPA y KA (kainato) generados a partir de las secuencias de cDNA, en las ramas del árbol se indica el valor de bootstrap (negrilla-ML y cursiva-By) y la proporción de sustituciones no-sinónimas con relación a las sustituciones sinónimas $(\omega)$. Los rombos indican cada grupo farmacológico y el triángulo indica los genes parálogos de Grin-2. 
divergencia entre las secuencias de Grik-1 relacionada con Grik-3 y las secuencias de Grik-4 relacionada con Grik-5. En la agrupación de AMPA se tiene la secuencia de Gria-1 como la más cercana al ancestro, de ella surge la secuencia de Gria-3 y de esta se orienta a las secuencias de Gria-2 relacionada con Gria-4. Por la determinación de la relación existente entre los sitios no-sinónimos y los sinónimos (valor $=\omega: \mathrm{dN} / \mathrm{dS}$ ), en donde los resultados obtenidos indican que la selección que actúa sobre las secuencias en este árbol es predominantemente purificadora.

\section{Sintenia cualitativa}

En la observación de las regiones de sintenia y la disposición de los bloques que la conforman (datos no mostrados), se puede establecer que en las regiones integradas por bloques amplios y con la misma distribución dentro del cromosoma, el proceso evolutivo ha permitido que estas regiones conserven las relaciones de ligamiento entre genes, debido a la baja frecuencia de recombinación, esto se puede observar entre las especies de primates en algunos cromosomas, por ejemplo en el cromosoma 4 y 19 de humano, chimpancé, orangután y el cromosoma 5 y 19 de macaco. Sin embargo algunos de los bloques de estas regiones, aunque son contiguos presentan alguna variación en la ubicación evidenciando la ocurrencia de un cambio o rearreglo cromosómico, el cual es fijado dentro de una población específica por eventos de recombinación, por ejemplo podría ser producto de una inversión, translocación, fusión o fisión de regiones génicas dentro del cromosoma; esto sucede entre las especies de humano comparado con chimpancé u orangután. En las sintenias en donde se observa la ocurrencia de varios bloques y diferente ubicación, se evidencia que el proceso evolutivo ha favorecido estos re-arreglos cromosómicos, evidenciándose al comparar las regiones de los iGluR de humano con los roedores (rata y ratón), esto es una señal de cómo actúa la especiación en el flujo génico. En esta primera aproximación se muestra cómo las regiones de sintenia son orientadas por procesos de selección que favorecen o no la recombinación génica, orientando a un tipo de evolución que es específica para una especie o población, es importante continuar con estudios cuantitativos que permitan identificar la secuencia ancestral y los tipos de re-arreglos que sobre ella sucedieron y han orientado la formación de las secuencias actuales.

\section{Discusión}

En términos generales se tiene que por cada inferencia filogenética obtenida se confirma que los receptores ino- trópicos de glutamato de los mamíferos podrían haber evolucionado a partir de un mecanismo más primitivo de señalización (20) por lo cual se presentan agrupaciones similares entre algunas especies de primates con roedores. La similitud de secuencia y, en algunos casos, la similitud en la estructura intrón-exón (25) sugiere un origen evolutivo común para todos los genes de iGluR $(11,26)$. En las topologías de los árboles se tiene que las secuencias se agrupan, en muchos casos de acuerdo a la clasificación farmacológica de las subunidades $(11,24)$, lo cual sugiere procesos de cambio en donde las regiones de información presentan características de acuerdo a cada subunidad por receptor. En todos los árboles se tiene la misma agrupación para los genes de Grin-2, es decir siempre se agrupan los genes de Grin-2A con Grin-2B y los de Grin-2C con los de Grin-2D, lo cual fortalece la hipótesis de que estos genes provienen de una secuencia ancestral en la que se presentó un evento de duplicación en donde posiblemente se tiene la acción de fuerzas de selección que guían el proceso evolutivo de estos genes, confirmando que estos genes son parálogos y han permanecido bajo selección purificadora desde la duplicación de la NR-2 ancestral y es probable que se conservara en sus proteínas la función común en sus dominios extracelulares y transmembranal (20).

Dentro de la evolución del cerebro humano se ha establecido por estudios previos, la importancia que tienen las secuencias génicas en el proceso de la regulación del tamaño y funcionalidad de este, por ejemplo en los primates se han identificado algunos genes que evidencian una rápida tasa de evolución, como los genes que codifican subunidades del receptor ionotrópico de glutamato GRIK4 y $\operatorname{GRIN} 2 \mathrm{~A}(1,2)$, por lo cual se asume que los genes que codifican proteínas específicas para el cerebro en primates tiene una tasa media de evolución en la escala de divergencia neutral más rápida que en los roedores (1). Sin embargo, esta hipótesis no logra ser confirmada en este trabajo que presenta una primera aproximación al proceso evolutivo de estas secuencias, en donde se evidencia una gran relación entre el proceso evolutivo de estos genes en el hombre con los roedores y no con los otros primates, por lo cual es necesario aplicar otros estudios para confirmar estas teorías de evolución. Finalmente se evidencia que la diversidad funcional en los receptores de glutamato está determinada por los genes que se expresan en una determinada neurona. Además, las subunidades de los iGluR están sujetas a alteraciones por splicing alternativo post-transcripcional, esto da lugar a una alta diversidad estructural y funcional originando ensamblajes heteromultiméricos de las subunidades $(18,19,27,28)$, lo cual está relacionado con la hipótesis inicial, en donde se postula que existe un alto 
grado de conservación funcional entre las especies porque las sustituciones entre los nucleótidos tienden a ser sinónimas y con modelos de evolución similares. Lo anterior se confirma, con la revisión general de los modelos de evolución molecular seleccionados los cuales son en su mayoría el modelo GTR con alguno de sus ajustes $(+\mathrm{I},+\mathrm{G},+\mathrm{IG})$, a partir de ellos en las inferencias filogenéticas, en donde la topología de los árboles presentan diferentes tasas de cambio de cada subunidad dentro de la especie, esto se encuentra relacionado con la longitud de las ramas dentro de cada agrupación. Existen algunas ramas que no se agrupan de una forma acorde con el receptor, esto puede suceder porque la secuencia anotada no corresponde a un cDNA de estos genes de iGluR, este es el caso de algunas secuencias en macaco, por último la hipótesis se confirma porque en la primera aproximación para establecer la tasa de cambio de las mutaciones sinónimas y las no-sinónimas se determina la relación existente entre estos sitios $(\omega)$, que por los resultados obtenidos se evidencia una selección purificadora, en donde las sustituciones no-sinónimas son detrimentales de la estructura y/o funcionalidad de la proteína, motivo por el cual la selección natural impide su fijación en las secuencias y aquellas que son introducidas se ubican en posiciones de los codones que no son relevantes para la determinación del respectivo aminoácido $(18,19,29)$.

\section{Conclusiones}

En este artículo se concluye que las secuencias de cDNA de esta familia génica muestran un comportamiento similar al postularse para ellas el modelo evolutivo de GTR con alguna de sus variables. En la primera aproximación a la relación de los sitios no-sinónimos con los sitios sinónimos se puede evidenciar que dentro de las subunidades se ha favorecido un proceso de selección estabilizadora o purificadora, por lo cual se impide que las sustituciones no-sinónimas se fijen a las secuencias y si son introducidas se fijan en regiones que no tienen impacto en la estructura y/o funcionalidad de la proteína. Se postula que en esta familia de genes de iGluR, los eventos de duplicación génica han favorecido una evolución divergente, por ello estos genes se ubican dispersos por todo el genoma, al mismo tiempo se confirma que los genes tipo Grin-2A a Grin-2D mantienen su agrupación, confirmando la teoría que estos genes se han producido por un gen ancestral en donde el evento de duplicación generó esta subfamilia de genes parálogos. También se plantea que estos genes de Grin se han formado a partir de la secuencia del gen Grin-1, el cual siempre se ve más cercano al ancestro. Adicionalmente se muestra que la filogenia del hombre está más relacionada con la filogenia de los murinidae (rata y ratón), esto porque sus estimaciones son muy similares confirmando que los receptores inotrópicos de glutamato de los mamíferos podrían haber evolucionado a partir de una secuencia ancestral y un mecanismo más primitivo de señalización. Paralelamente los procesos de recombinación que generan los rearreglos en regiones cromosómicas están orientados por procesos de selección que permiten la especiación en el flujo génico, presentándose regiones características de cada especie. Los procesos de sintenia son altamente conservados entre el hombre, el chimpancé, el orangután y el macaco, mientras que al comparar la región del cromosoma del hombre que codifica los iGluR, se presenta una alta tasa de recombinación que es observada en la generación de bloques sinténicos pequeños con diferente ubicación dentro del cromosoma de la rata y el ratón. Por último evidenciamos que la evolución de las subunidades del receptor muestra tasas diferentes y grados diferentes de especialización, por lo cual cada receptor tipo NMDA, AMPA y KA tiene un comportamiento estructural diferente, por lo cual postulamos que estos receptores no son una sola molécula sino un complejo hetero-molecular y dinámico.

\section{Agradecimientos}

Al grupo de bioinformática de la Pontificia Universidad Javeriana, al grupo de proteínas de la Universidad Nacional, al PhD. Paulo Vinuesa de la Universidad Nacional Autónoma de México, a PhD Úrsula Ramírez del Instituto de genética de la Universidad Nacional, a PhD Diana Alvarez, PhD Janneth González y MSc Fabio Avellaneda de la Pontificia Universidad Javeriana.

\section{Financiación}

Este trabajo fue desarrollado en el Laboratorio Computacional del Grupo de Bioquímica Computacional, Estructural y Bioinformática de la Universidad Javeriana y en equipos de uso propio de los autores del mismo.

\section{Conflicto de Intereses}

Los autores no presentan conflicto de intereses.

\section{Referencias}

1. Lahn B, Dorus S, Vallender, E, Evans P, Anderson J, Gilbert S, Mahowald M, Wyckoff G, Malcom C. Accelerated evolution of nervous system genes in the origin of Homo sapiens. Cell. 2004; 119:1027-1040. 
2. Bradbury J. Molecular insights into human brain evolution. Plos Biology. 2005; 3:367-370.

3. Allen J, Bruss J, Damasio H. Estructura del cerebro humano. Investigación y Ciencia. 2005: 69-77.

4. Varki A. How to make and ape brain. Nature Genetics. 2004; 36(10):1034-1037.

5. Burki F. Kaessmann H. Birth and adaptive evolution of a hominoid gene that supports high neurotransmitter flux. Nature Genetics. 2004; 36 (10):1061-1063.

6. Boulter J, Hollmann M, O'Shea-Greenfield A, Hartley M, Deneris E, Maron C, Heinemann S. Molecular cloning and functional expression of glutamate receptor subunit genes. Science. 1990; 249:1033-1037.

7. Dingledine R, McBrain C, McNamara JO. Excitatory amino acid receptors in epilepsy. Trends Pharmacology. 1990; 11:334-338.

8. Dingledine R, McBrain C. (1998). Glutamate and aspartate, in Basic Neurochemistry. $6^{\text {th }}$ edition, Lippincott Raven, Philadelphia.

9. Dingledine R, Borges K, Bowie D, Traynelis SF. The Glutamate receptors ion channels. Pharmacology Review. 1999; 51:7-61

10. Vandongen A. (2009). Biology of the NMDA receptor. Duke University Medical Center North Carolina. Taylor \& Francis Group.

11. Egebjerg J, Schousboe A, Krogsgaard-Larsen P. (2002). Glutamate and GABA receptors and transporters; Structure, function and pharmacology. Taylor \& Francis Group.

12. Gereau R, Swanson G. (2008). The glutamate receptors. Humana Press.

13. Kutsuwada T, Kashiwabuchi N, Mori H, Sakimura K, Kushiya E, Araki K, Meguro H, Masaki H, Kumanishi T, Arakawa M, Mishina M. Molecular diversity of the NMDA receptor chanel. Nature. 1992; 358:36-41.

14. Sheng M, Cummings J, Roldman LA, Jan YN, Jan LY. Changing subunit composition of heteromeric NMDA receptor during development of rat cortex. Nature. 1994; 368:144-147.

15. Bai G, Kusiak JW. Functional analysis of the proximal 5 '-flanking region of the N-methyl-D-aspartate receptors subunit gene, NMDAR1. The Journal of Biological Chemistry. 1995; 270 (13):7737-7744.

16. Bai G, Kusiak JW. Nerve growth factor UP-regulates the N-methyl-D-aspartate receptor subunit 1 promoter in PC12 cells. The Journal of Biological Chemistry. 1997; 272 (9):5936-5942.

17. Gasic GP, Heinemann S. Receptors coupled to ionic channels: the glutamate receptor family. Current Opinion in Neurobiology. 1991; 1: 20-26.
18. Mejía-Guerra, MK, Lareo LR. In Silico Identification of regulatory elements of GRIN1 genes. OMICS: Journal of Integrate Biology. 1995; 9(1):106-115.

19. Mejía-Guerra, MK, Lareo LR. (2006). Aproximaciones computacionales para la identificación de promotores eucariotas tipo II. Universitas Scientiarum. 2006; 11:35-47.

20. Ryan T, Emes R, Grant S, Komiyama N. Evolution of NMDA receptor cytoplasmic interaction domains: implications for organization of synaptic signaling complexes. BMC Neuroscience. 2008; 9(6):14712202 .

21. Borges K, Dingledine R. AMPA receptors: molecular and functional diversity. Prog Brain Res. 1998; 116: $140-157$.

22. Nei M, Rooney AP. Concertred and "Birth-and-death" Evolution in Multigene families. Annual Review in Genetics. 2005; 39:121-152.

23. Moran L. Departamento de bioquímica de la Universidad de Toronto. Web site [en-linea]: http:// sandwalk.blogspot.com/2007/01/evolution-of-genefamilies.html. Consultado en febrero de 2010.

24. Das, S., Sasaki, Y., Rothe, T., Louis, S., Premkumar, M., Takasu., M., Crandall, J., Dikkes, P., Conner, D., Rayudu, P., Cheung, W., Chen, V., Lipton, S., Nakanishi, N. Increased NMDA current and spine density in mice lacking the NMDA receptor subunit NR3A. Nature 1998; 393:377-381.

25. Suchanek B, Seeburg PH, Sprengel R. Gene structure of the murine $\mathrm{N}$-methyl $\mathrm{D}$-aspartate receptor subunit NR2C. Journal of Biological Chemistry. 1995; 270: 41-44.

26. Chenu C, Serre, CM, Raynal C, Burt-Pichat B, Delmas PD. Glutamate receptors are expressed by bone cells and are involved in bone resorption. Bone. 1998; 22:295-299.

27. Hawkins LH, Chazot PL, Stephenson FA. Biochemical evidence for the co-association of three N-methylDaspartate (NMDA) R2 subunits in recombinant NMDA receptors. Journal of Biological Chemistry. 1999; 274:27211-27218.

28. Hawkins LH, Law A, Eastwood S. Glutamate receptors ad transporters in the hippocampus in schizophrenia. Ann N Y Acad Sci . 2003; 1003:94-101.

29. Kashiwagi K, Pahk AJ, Masuko T, Igarashi K, Williams K. Block and modulation of N-methyl-D-aspartate receptors by polyamines and protons: Role of amino acid residues in the transmembrane and pore-forming regions of NR1 and NR2 subunits. Molecular Pharmacology. 1997; 52: 701-713. 